\title{
Evaluation of a simple and sensitive sensory method for measuring rancidity in soybean oils
}

\author{
By J. R. López-Aguilar', G. Valerio-Alfaro², J.A. Monroy-Rivera², L.A. Medina-Juárez², \\ M. O'Mahony ${ }^{4}$ and O. Angulo ${ }^{2^{*}}$
}
${ }^{1}$ Division Académica de Ciencias Agropecuarias, Universidad Juárez Autónoma de Tabasco, México.
${ }^{2}$ Unidad de Investigación y Desarrollo en Alimentos, Instituto Tecnológico de Veracruz, México.
${ }^{3}$ Departamento de Investigaciones Científicas y Tecnológicas, Universidad de Sonora, México.
${ }^{4}$ Department of Food Science and Technology, University of California, U.S.A.
${ }^{*}$ Corresponding author: Prof. Ofelia Angulo. Unidad de Investigación y Desarrollo en Alimentos, Instituto Tecnológico de Veracruz. M.A. de Quevedo 2779, Veracruz, 91860 Ver. México. TEL. 229-9341478 Ext. 125 FAX: 229-9345701 Ext. 201. Email: oangulo@ itver.edu.mx

\section{RESUMEN}

Evaluación de un método sensorial sencillo y efectivo para determinar la rancidez en aceite de soja

El propósito de este trabajo fue evaluar la eficacia de la prueba de selección forzada de dos alternativas (2-AFC) para determinar la rancidez en aceite de soja. La correlación entre la calidad química y los atributos sensoriales de los aceites fue el segundo objetivo del trabajo. El perfil de ácidos grasos, ácidos grasos libres (AGL), índice de anisidina (VA), índice de peróxidos (VP), dienos conjugados (DC), color, Rancimat y TOTOX se midieron en aceites de cuatro plantas procesadoras de aceite comestible de soja. Los atributos sensoriales del aceite se midieron utilizando la prueba oficial de la Sociedad Americana de Químicos de Aceites (AOCS) y el atributo de rancidez se evaluó usando la prueba 2-AFC. Todos los aceites satisficieron los criterios de calidad química para los aceites de soja. El método sensorial 2-AFC fue eficaz en determinar diferencias pequeñas en rancidez. Se encontró correlación entre los valores de anisidina y Rancimat y las diferencias sensoriales en rancidez (d').

PALABRAS-CLAVE: 2-AFC - Aceite comestible - Aceite de soja - Atributos sensoriales - Rancidez.

\section{SUMMARY}

Evaluation of a simple and sensitive sensory method for measuring rancidity in soybean oils

The purpose of this study was to evaluate the efficacy of the 2 Alternative Forced Choice (2-AFC) sensory method in detecting rancidity in soybean oils. Additionally, correlations between the physico-chemical quality and the sensory attributes of edible soybean oils were studied. Soybean oil samples from four different plants were analyzed for their fatty acid profile, Free fatty acid (FFA), Anisidine Value (AV), Peroxide Value (PV), Conjugated Dienes (CD), Colour, Rancimat and TOTOX. The sensory attributes of the oils were measured using The American Oil Chemists Society (AOCS) sensory method and additionally, rancidity was assessed using the 2-AFC sensory method. All oil samples fit the quality control criteria for edible soybean oil. The 2-AFC method was sensitive to small differences in rancidity. Differences in anisidine value and Rancimat were correlated to the difference in rancidity (d') among oils.

KEY-WORDS: 2-AFC - Edible oil - Rancidity - Sensory attributes - Soybean oil.

\section{INTRODUCTION}

Soybean is the most important oilseed in the world market. During 2002-2003, 62\% of the 314 million metric tons of the worldwide oilseed production was obtained from soybean (www. soyatech.com). Soybean oil consumption in the United States and Mexico is higher than for any other vegetable oil (Asbridge, 1995). Soybean oil contains the essential fatty acids (18:2 $\omega 6$ and 18:3 $\omega 3$ ) and thus makes it very attractive for human nutrition (Carvajal-Zarrabal y Angulo-Gerrero, 1997). However, the high concentrations of polyunsaturated fatty acids (PUFA) in soybean oils increase the oil's susceptibility to oxidation. Soybean oil has been frequently associated with a fishy flavor due to the presence of oxidation breakdown products from linolenic acid.

Sensory attributes of edible oils must be carefully monitored to maintain the flavor quality of the oil. The American Oil Chemists Society (AOCS, 1994) recommends using a sensory descriptive method to rate the sensory attributes of soybean oil. Selected sensory attribute intensities are estimated using a structured 10-point category scale. Such scales are designed to measure large differences in flavor among oils. However, perceptible differences may sometimes be small but still important. Therefore, panelists must be highly trained, so that they are very sensitive so that differences that might seem small to the ordinary person would seem great to them. 
Because of the difficulties in sensory assessments, it is always tempting to substitute a sensory panel with instrumental measures. Accordingly, studies have compared instrumental and sensory quality measurements of oils and other oil based products (Nor Aini et al., 1992; Hawrysh et al., 1995; Jacobsen, 1999; Thompkins and Perkins, 1999; Caiping et al., 2003; Gomez-Alonso et al., 2004). The hexanal/nonanal ratio has been associated with the rancid attribute in oxidized olive oil (Morales et al., 1997).

Apparently, the most common attribute of 'offflavor' is rancidity (Jacobsen, 1999) which suggests that a targeted test for rancidity would be appropriate. Furthermore, such a test would involve less time and cost. Sensory difference tests, such as the 2-Alternative Forced Choice (2-AFC) method, sometimes called the paired comparison method, can be used to monitor rancidity with no need for highly trained personnel (Lawless and Heymann, 1988). For the 2-AFC test, the panelists only need to know how to recognize rancid oil. This is normally well known by oil factory quality control workers.

Sensory difference tests are designed to measure small differences among oils, without the need for extensive training. These tests are very sensitive and this compensates for the lack of intensive training required for descriptive analysis. The 2-AFC test is one of the most powerful and sensitive difference tests (Ennis, 1990). The test results can describe the degree of rancidity using various numerical measures. Perhaps the most useful index, is the one commonly used in experimental psychology, denoted as the $d^{\prime}$ index (Green and Swets, 1966). This index is a measurement of the perceived difference between two oils expressed in units of standard deviation of the perceived variability of a single oil. It is essentially a signal-to-noise ratio.

The purpose of this study was to explore the sensitivity of the 2-AFC sensory method in detecting rancidity in oils. Such a method could be used as a quality control tool when the rancid attribute was the major contributor to oil 'off-flavor'. Because the study was a comparison between commercial oils on the market, rather than a storage study, any difference in rancidity would be expected to be small. A second goal was to examine any relationship between the quality parameters commonly measured by the industry (Free Fatty Acids (FFA), Peroxide Value (PV), Anisidine Value (AV), Conjugated Dienes (CD), colour and oxidative stability) and the sensory judgments of rancidity.

\section{MATERIALS AND METHODS}

Samples. Samples were received from four different Mexican oil factories (four samples from each one) namely La Patrona, Imperial, La Gloria, and Nutrioli. Samples were stored at $-20^{\circ} \mathrm{C}$ in dark glass bottles until used.
Fatty acid profile. Oil samples were saponified and methylated according to the AOCS procedures Ce 2-66 (Official Methods and Recommended Practices, 1994). Fatty Acid Methyl Esters (FAME) were analyzed by gas chromatography equipped with flame ionization detector (model 3400, Varian, Mexico City, Mexico). A fused silica capillary column coated with $100 \%$ biscyanopropyl polysiloxane as the stationary phase (SP-2560, $100 \mathrm{~m} \times 0.25 \mathrm{~mm}$, id $20 \mu \mathrm{m}$ thickness, Supelco Bellefonte, PA) was used. The carrier gas was nitrogen $\left(20 \mathrm{~cm}^{3} / \mathrm{s}\right.$ flow rate). The oven temperature programme was as follows: $140^{\circ} \mathrm{C}(5 \mathrm{~min}), 140-170^{\circ} \mathrm{C}\left(4^{\circ} \mathrm{C} / \mathrm{min}\right), 170^{\circ} \mathrm{C}$ (3 min), $170-200^{\circ} \mathrm{C}\left(1.5^{\circ} \mathrm{C} / \mathrm{min}\right)$ and $200^{\circ} \mathrm{C}(10 \mathrm{~min})$. Injector and detector temperatures were held at $250^{\circ} \mathrm{C}$. FAME peaks were identified by comparison with the retention time of the respective standards (Sigma Chemical Co., St Louis MO). Samples were measured in triplicate.

Quality and Stability Parameters. The American Oil Chemists Society standard methods (Official Methods and Recommended Practices, 1994) were used for: color (Cc 13e-92), Free Fatty Acids (Ca 5a-40), Peroxide Value (Cd 8-53), and Anisidine Value (Cd 18-90). The oil stability index was determined using the Methrom Rancimat (Methrom 679; Herisau, Switzerland) and the TOTOX value $(2 \mathrm{PV}+\mathrm{AV})$. For the Rancimat index, the oil sample size was $3.0 \mathrm{~g}$, the air flow rate was $20 \mathrm{~L} / \mathrm{h}$, and the temperature was set at $110^{\circ} \mathrm{C}$. All tests were performed in triplicate.

Sensory Analysis. Eight judges (3M; 5F age range 19-23 yrs) were used to compare the two sensory test methods. Judges were selected on their ability to recognize rancidity. The 2-AFC tests were performed first. For this, a judge was presented with two oils, asked to taste them and judge which one was the more rancid. Oil samples $(5 \mathrm{ml})$ were presented to the judges at $51^{\circ} \mathrm{C}$ in $30 \mathrm{ml}$ crystal glasses, were tasted and spat out. Between tasting oils, judges were required to rinse with warm water $\left(38-40^{\circ} \mathrm{C}\right)$. They were required to rinse at least once but no more than six times, to avoid problems of forgetting. In a single session, four pairs of oils were presented. There were six possible pairings and over the eighteen experimental sessions that judges were required to attend, each of the six pairings was tested a total of twelve times in random order. Each session lasted 10-15 min.

After completing the first experiment, judges were trained for the descriptive analysis procedure as recommended by AOCS ( $\mathrm{Cg} 2-83$, Official Methods and Recommended Practices, 1994). Judges came every weekday for 16 weeks, each training session lasting approximately $40 \mathrm{~min}$. The training involved judges learning to recognize the sensory attributes of nutty, buttery, corny, hydrogenated, rancid, beany, rubbery, weedy, grassy, burned, painty, and fishy. These were learned by giving the judges standard stimuli defined by AOCS to represent these attributes in oils. Judges also learned to use a 10-point category 
intensity scale. After training, judges were given a single oil and asked to rate the intensity of each of the attributes. They were allowed to retaste the oil as often as necessary and could rinse with warm water, if desired, between tastings. Each of the four oils was presented in separate sessions three times, for a total of 12 sessions. Each session lasted approximately $20 \mathrm{~min}$.

\section{Statistical Analysis}

Data from the analytical tests and descriptive analysis of the oils were analyzed by ANOVA $(p<0.05)$. Mean significance was tested using Fisher LSD test $(p<0.05)$. Data from the 2-AFC test were analyzed using beta-binomial statistics ( $\mathrm{Bi}$ and Ennis, 1998; Bi and Ennis, 1999; Bi et al., 2000). Correlation coefficients were established using the Pearson's product-moment correlation ( $r$ ) and by Spearman's $\rho$ correlations.

\section{RESULTS AND DISCUSSION}

Fatty Acid Profile: The fatty acid profile of the soybean oils was consistent with that of a typical soybean oil reference (Malcomson, 1995), (Table 1). It is important to remark on the presence of trans fatty acids in all the samples. This has also been reported by Medina-Juarez et al., (2000) who found levels of trans fatty acids at concentrations between 0.90 and $2.93 \%$ in soybean oil produced in Mexico. They attributed this to the high temperature (240$260^{\circ} \mathrm{C}$ ) used during deodorization. Kellens (1997) suggests temperatures of $230-235^{\circ} \mathrm{C}$ during deodorization to avoid trans fatty acid formation and major tocopherol losses $(<25 \%)$. However, if the deodorization emperature is too low, FFA levels might remain high and this is not desirable for the oil stability. A compromise between temperature and all other deodorization parameters should be attained to reduce the amount of trans fatty acids in edible oils.

Free Fatty Acids. All the oil samples contained FFA levels around $0.04 \%$ (Table 2). No significant differences in free fatty acids were found among the oils. These FFA values fell near the upper side of the recommended levels for refined oils
(Malcomson, 1995). The FFA level recommended for deodorized oils ranges from $0.03-0.05 \%$ (Norma Oficial Mexicana, 1985). The high temperatures used during deodorization favor the reduction of FFA but promote the formation of trans fatty acid. Other deodorization parameters (Steam percentage, vapor pressure, time, etc) should also be considered for optimizing oil deodorization.

Peroxide Value. Results for peroxide values are given in Table 2. Good quality soybean oil should not exceed peroxide values of 1.0. All sample oils exceeded this value except one (Nutrioli). However, no significant differences $(p<0.05)$ were observed among oil samples. Peroxide value has no effect on oil flavor, therefore no correlation was found with the sensory quality of the oil (2-AFC test).

Conjugated dienoic acids. The results of this study (Table 2) showed no significant differences among the samples analyzed, although the Nutrioli brand oil contained the lowest CD level. Similar results were reported for other Mexican soybean oils, 0.17-0.69\% (Medina-Juarez et al., 2000). These intermediate components can react with molecular oxygen to form conjugated hydroperoxides (Frankel, 1998). The extent of double bond displacement correlates well with the degree of peroxidation occurring in linoleic and linolenic acids in unsaturated oils. Double bonds can also shift to form CD during partial hydrogenation or deodorization of oil if the temperature rises above $245^{\circ} \mathrm{C}$ (White, 1995).

Anisidine Value. Freshly refined soybean oil with good stability is expected to have anisidine values below 2 (Lusas and Hernández, 1993). AV represents secondary oxidation products such as aldehydes. The highest value observed in this study corresponded to La Gloria oil $(2.31 \mathrm{mmol} / \mathrm{kg})$ and the lowest was for Nutrioli oil (Table 2). It has been reported that oils rich in polyunsaturated fatty acids, such as soybean oil, may have AV between 1 and 10. Henning (1976) suggests the use of AV to measure the degree of oxidation and the efficiency of the refining process of the oil. This is the only chemical parameter that showed significant differences among samples.

Table 1

Fatty acid profile in soybean oils

\begin{tabular}{lccccc}
\hline Fatty Acid (wt \%) & PATRONA & GLORIA & IMPERIAL & NUTRIOLI & REFERENCE \\
\hline PALMITIC (C16:0) & $10.71 \pm 0.26$ & $9.939 \pm 0.01$ & $10.17 \pm 0.83$ & $10.84 \pm 0.04$ & $8.0-13.3$ \\
STEARIC (C18:0) & $4.24 \pm 0.04$ & $3.88 \pm 0.23$ & $3.85 \pm 0.02$ & $4.23 \pm 0.07$ & $2.4-5.4$ \\
OLEIC (C18:1) & $23.28 \pm 0.42$ & $22.47 \pm 0.63$ & $23.29 \pm 0.09$ & $23.31 \pm 0.7$ & $17.7-26.1$ \\
LINOLEIC (C18:2) & $53.4 \pm 0.2$ & $53.12 \pm 0.48$ & $53.13 \pm 0.31$ & $53.46 \pm 0.45$ & $49.8-57.1$ \\
ARACHIDIC (C20:0) & $0.32 \pm 0.1$ & $0.26 \pm 0.03$ & $0.28 \pm 0.08$ & $0.32 \pm 0.09$ & $0.1-0.6$ \\
LINOLENIC Cis (C18:3) & $6.28 \pm 0.32$ & $6.73 \pm 0.45$ & $6.64 \pm 0.32$ & $6.52 \pm 0.09$ & $5.5-9.5^{*}$ \\
LINOLENIC Trans & $0.89 \pm 0.16$ & $0.69 \pm 0.03$ & $0.76 \pm 0.17$ & $0.87 \pm 0.17$ & \\
\hline
\end{tabular}

\footnotetext{
${ }^{\star}$ Reported as total linolenic acid.
} 
Table 2

Analytical tests for soybean oils

\begin{tabular}{lcccc}
\hline TESTS & PATRONA & GLORIA & IMPERIAL & NUTRIOLI \\
\hline FFA (\%) & $0.044 \pm 0.054^{\mathrm{a}}$ & $0.053 \pm 0.012^{\mathrm{a}}$ & $0.043 \pm 0.008^{\mathrm{a}}$ & $0.044 \pm 0.010^{\mathrm{a}}$ \\
PV (mEq/kg) & $1.09 \pm 0.346^{\mathrm{a}}$ & $1.365 \pm 0.572^{\mathrm{a}}$ & $1.365 \pm 0.300^{\mathrm{a}}$ & $0.908 \pm 0.280^{\mathrm{a}}$ \\
CD $(\%)$ & $0.365 \pm 0.07^{\mathrm{a}}$ & $0.355 \pm 0.108^{\mathrm{a}}$ & $0.423 \pm 0.106^{\mathrm{a}}$ & $0.286 \pm 0.064^{\mathrm{a}}$ \\
AV (mmol/kg) & $0.561 \pm 0.152^{\mathrm{a}}$ & $2.311 \pm 0.998^{\mathrm{b}}$ & $1.368 \pm 0.944^{\mathrm{ab}}$ & $0.529 \pm 0.450^{\mathrm{a}}$ \\
COLOUR & $10 \mathrm{~A} 0.2 \mathrm{R}^{\mathrm{a}}$ & $10 \mathrm{~A} 0.1 \mathrm{R}^{\mathrm{a}}$ & $10 \mathrm{~A} 0.2 \mathrm{R}^{\mathrm{a}}$ & $10 \mathrm{~A} 0.3 \mathrm{R}^{\mathrm{a}}$ \\
RANCIMAT (h) & $8.77 \pm 0.13^{\mathrm{a}}$ & $13.40 \pm 0.14^{\mathrm{b}}$ & $13.45 \pm 0.21^{\mathrm{b}}$ & $10.32 \pm 0.53^{\mathrm{c}}$ \\
TOTOX & $2.745 \pm 0.76^{\mathrm{a}}$ & $5.041 \pm 2.01^{\mathrm{a}}$ & $4.101 \pm 1.56^{\mathrm{a}}$ & $2.34 \pm 0.433^{\mathrm{a}}$ \\
\hline
\end{tabular}

Scores given are mean values \pm standard deviation

Means with different superscripts are significantly different $(p<0.05)$

Colour. All samples analysed achieved the color criteria established by Official Mexican Standards, 20Y 3R (Table 2).

Oxidative Stability. The TOTOX value estimates the oxidative stability of oil by including the Peroxide and Anisidine Values of the oil; that is the primary and secondary oxidative compounds. In this study, La Gloria and Imperial brands had TOTOX levels above the expected value (4.0) for good quality oils (Table 2). However, no significant difference was observed in TOTOX values of all the samples analysed. According to the Rancimat test, La Gloria and Imperial also had the highest Rancimat value (Table 2). It is important to mention that, on their labels, these two oils reported the highest antioxidant (TBHQ) and citric acid levels used to preserve the oil stability, which may contribute to the highest Rancimat values found in these oils. There were significant differences $(p<0.05)$ among the Rancimat oxidative stability of some oils, the highest being for La Gloria and Imperial brands (13.4 h) and the lowest for La Patrona brand (8.7 h).

Sensory Evaluation. For the 2-AFC tests, the proportion of tests performed correctly was noted for each judge and for each one of the six possible pairings of the commercial soybean oils. These data were combined over the eight judges (6 pairings $x 8$ judges) giving a total proportion of correct tests for each oil pairing (from 48). From these proportions, $\mathrm{d}^{\prime}$ values were obtained using tables ( $\mathrm{Bi}$ et al., 1997). Testing whether the differences in perceived rancidity between the oils were statistically significant can be accomplished using binomial statistics. However, because judges and replicate tastings were combined, a problem arises with the binomial statistics. The problem is called overdispersion and is due to the fact that not all judges have the same sensitivity. The problem is solved, however, by using an adjustment to the binomial test called the beta-binomial ( $\mathrm{Bi}$ and Ennis, 1998; Bi and Ennis, 1999; Bi et al., 2000). The d' values for the six possible pairings of the oils are given in Table 3 . Also given are the significance levels, the probabilities that the differences indicated by the $d^{\prime}$ values were merely due to chance. Values lower than 0.05 are generally considered to be significant. From the table, it can
Table 3

d' values for 2-AFC tests and their significance levels.

\begin{tabular}{lcc}
\hline OILS & d' & $\begin{array}{c}\text { Significance } \\
\text { levels }^{*}\end{array}$ \\
\hline Patrona vs. Gloria & 1.10 & 0.00 \\
Patrona vs Imperial & 0.86 & 0.00 \\
Patrona vs Nutrioli & 0.17 & 0.18 \\
Gloria vs Imperial & 0.52 & 0.003 \\
Gloria vs Nutrioli & 0.72 & 0.00 \\
Imperial vs Nutrioli & 0.58 & 0.001 \\
\hline
\end{tabular}

*Significance levels less than 0.05 are generally considered to be significant (beta binomial test)

be seen that the 2-AFC tests indicated significant differences for five of the six possible pairings.

For the official AOCS sensory descriptive analysis method, the mean scores (from 3 experimental sessions) for each of the 12 attributes for each of the 4 oils were recorded for each judge. These values are given in Table 4 . The statistical significance of the differences among the means was determined using ANOVA and LSD tests. From the table, it can be seen that for rancidity none of the means were significantly different. Therefore, the 2-AFC difference test was more sensitive to differences than the descriptive analysis.

A second goal of the study was to determine whether $d$ ' values would indicate any associations between the various chemical parameters (AV, PV, $\mathrm{CD}$ and FFA) and the sensory evaluation of rancidity. The usual approach to such a problem is to seek correlations between instrumental and sensory parameters. The correlation method usually chosen is Pearson's product-moment correlation ( $r$ ), which determines the strength of a linear relationship between the two variables. However, linear relationships are comparatively rare in nature and such an approach may miss a monotonic relationship. Therefore, Spearman's $\rho$ might be more suitable. This is a linear correlation between the ranks of the values measured for the two variables and is thus sensitive to detecting monotonic relationships (O’Mahony, 1986). However, for a 
Table 4

Mean intensity scores for flavor descriptors for soybean oils

\begin{tabular}{lcccc}
\hline FLAVOR & PATRONA & GLORIA & IMPERIAL & NUTRIOLI \\
\hline Nutty & $8.1 \pm 2.2^{\mathrm{ab}^{\mathrm{a}} \neq}$ & $7.12 \pm 1.9^{\mathrm{b}}$ & $7.75 \pm 1.8^{\mathrm{ab}}$ & $9.09 \pm 1.6^{\mathrm{a}}$ \\
Buttery & $7.05 \pm 2.0^{\mathrm{a}}$ & $5.94 \pm 2.7^{\mathrm{a}}$ & $6.03 \pm 2.4^{\mathrm{a}}$ & $6.93 \pm 2.2^{\mathrm{a}}$ \\
Corny & $7.2 \pm 1.7^{\mathrm{a}}$ & $7.08 \pm 1.5^{\mathrm{a}}$ & $6.48 \pm 2.3^{\mathrm{a}}$ & $6.61 \pm 2.1^{\mathrm{a}}$ \\
Beany & $4.9 \pm 2.3^{\mathrm{a}}$ & $6.40 \pm 2.0^{\mathrm{a}}$ & $6.0 \pm 2.3^{\mathrm{a}}$ & $6.0 \pm 2.0^{\mathrm{a}}$ \\
Hydrogenated & $8.08 \pm 1.7^{\mathrm{a}}$ & $6.83 \pm 1.6^{\mathrm{a}}$ & $6.94 \pm 2.2^{\mathrm{a}}$ & $7.0 \pm 2.1^{\mathrm{a}}$ \\
Rancid & $5.89 \pm 2.7^{\mathrm{a}}$ & $6.58 \pm 2.2^{\mathrm{a}}$ & $6.06 \pm 2.5^{\mathrm{a}}$ & $6.08 \pm 2.5^{\mathrm{a}}$ \\
Burned & $6.33 \pm 2.1^{\mathrm{ab}}$ & $7.0 \pm 1.4^{\mathrm{b}}$ & $6.67 \pm 2.0^{\mathrm{ab}}$ & $4.72 \pm 2.0^{\mathrm{a}}$ \\
Weedy & $7.75 \pm 0.95^{\mathrm{a}}$ & $8.0 \pm 2.6^{\mathrm{a}}$ & $7.43 \pm 1.7^{\mathrm{a}}$ & $7.8 \pm 1.0^{\mathrm{a}}$ \\
Grassy & $7.0 \pm 1.8^{\mathrm{a}}$ & $7.08 \pm 2.3^{\mathrm{a}}$ & $6.87 \pm 1.8^{\mathrm{a}}$ & $6.7 \pm 2.3^{\mathrm{a}}$ \\
Rubbery & $6.4 \pm 1.9^{\mathrm{a}}$ & $7.2 \pm 1.3^{\mathrm{a}}$ & $7.44 \pm 1.7^{\mathrm{a}}$ & $7.25 \pm 1.8^{\mathrm{a}}$ \\
Painty & $6.5 \pm 2.0^{\mathrm{a}}$ & $6.38 \pm 1.9^{\mathrm{a}}$ & $6.64 \pm 2.1^{\mathrm{a}}$ & $6.89 \pm 1.9^{\mathrm{a}}$ \\
Fishy & $6.15 \pm 3.0^{\mathrm{a}}$ & $7.5 \pm 0.7^{\mathrm{a}}$ & $7.33 \pm 2.0^{\mathrm{a}}$ & $4.80 \pm 2.7^{\mathrm{a}}$ \\
\hline
\end{tabular}

*Scores given are mean values \pm standard deviation

* Means with different superscripts are significantly different $(p<0.05)$

relationship that shows a general increasing trend without monotonicity, the product-moment correlation might be more suitable. In the present study, both correlation methods were used.

In the literature for oils, Thompkins and Perkins (1999) reported a correlation ( $r=0.82)$ between AV and overall odor intensity, while Gomez-Alonso et al., (2004) found no relationship between FFA, PV and $\mathrm{AV}$ and rancidity threshold. However, they did suggest that 2,4 decadienal was relevant. For these studies (Nor Aini et al., 1992; Hawrysh et al., 1995; Jacobsen, 1999; Gomez-Alonso et al., 2004) the range of chemical values was far greater than in the present study; their range was such that the oils varied from acceptable to unacceptable. Thompkins and Perkins (1999) did not give actual values. With the comparatively small variation in levels of oxidation between the present oils, which were presumably all acceptable, the rancidity differences were smaller than in the studies mentioned above. A correlation between sensory measures of rancidity per se and instrumental measures would also be expected to be small, because of the small rancidity range. This was indicated by the lack of significance for the differences between rancidity scores obtained by the AOCS descriptive analysis method.

Because any changes in rancidity would be small, the 2-AFC test was necessary to detect them. Thus, if there was (more American) any chance of obtaining sensory-instrumental correlations, it would be with d' values. Because d' values are sensory measures of differences among the oils, they should be correlated with instrumental measures of differences among the oils. The appropriate Pearson's Product-Moment $(r)$ and Spearman's $\rho$ values were computed. Pearson's Product-Moment values were $0.80^{*}$ for $\mathrm{AV}, 0.43$ for FFA, 0.28 for PV, 0.59 for CD, $0.76^{*}$ for Rancimat and 0.50 for TOTOX value. For Spearman's $\rho$, they were 0.49 for AV, 0.29 for FFA, 0.45 for PV, $-0.83^{*}$ for $C D$, $0.83^{*}$ for Rancimat and 0.71 for TOTOX value ( ${ }^{*}$ indicates statistical significance $p<0.05$, one-tailed).
Rancimat values correlated with sensory differences in rancidity. For CD, Spearman's $\rho$ was negatively correlated, indicating a significant monotonic decrease in rancidity with increasing $C D$. The authors are aware of no prior reports of this. Furthermore, this result is surprising because changes in CD would not be expected to be related to chemical changes in rancidity. Therefore, this result can provisionally be seen as due to chance. Finally, there was a significant correlation ( $r$ ) between rancidity and $\mathrm{AV}$ value. Literature results regarding $\mathrm{AV}$ and sensory data are contradictory. In fact, while Thompkins and Perkins (1999) found a high correlation ( $r=0.82)$, Jacobsen (1999) reported no correlation between sensory data and AV. Jacobsen states that the lack of correlation between AV and sensory data may indicate the low sensitivity and specificity of the AV method to detect changes in concentration of volatiles responsible for the 'off-flavor' detected by sensory tests. However, Thompkins and Perkins (1999) reported highly significant correlations between AV and hexanal, which is the main breakdown product of linoleic acid. In any case, both papers agree on the importance of performing sensory evaluation to better assess stability on fat-containing products. Morales et al., (1997) reported that since hexanal is present in the original flavor of some oils (virgin olive oil) nonanal measurement might be a better predictor of oxidation onset. These authors suggest the use of hexanal/naonanal ratio as a way to detect the beginning of oxidation and its evolution. Correlation between this ratio and rancidity in soybean oils deserves further investigation.

The 2-AFC method was seen to be more sensitive to differences in rancidity than the official AOCS descriptive analysis method. Furthermore, the method indicated correlations between sensory measurements of rancidity and instrumental measurements that the official AOCS method could not. 
Not only was the 2-AFC method more sensitive, it was less time-consuming and thus less costly. The 2-AFC method required approximately 2 hours and 40 min of testing per judge. The AOCS method required 53 hours $20 \mathrm{~min}$. For the latter, all eight judges were trained and tested together, so the total for eight judges was the same as for one judge. For the 2-AFC method, if all judges were tested simultaneously, the total testing time would be 2 hours $40 \mathrm{~min}$. If groups of the eight judges were tested in say four separate sessions, the total testing time would still only be $19 \%$ of the total time with the AOCS method. The present study used eight judges but 4-6 judges who were able to detect rancidity would be adequate.

Considering that rancidity might be the main concern in quality control, the 2-AFC method is thus eminently suitable for testing at the factory level. It is simple and sensitive. Should other 'off-flavors' be occasionally detected, then descriptive analysis would be suitable to identify the 'off-flavor'. However, it is not cost-effective for each company to have its own descriptive panel. Therefore, it would be advisable for companies to pool their resources to support an independent descriptive panel that can service all companies when needed.

\section{CONCLUSIONS}

The 2-AFC method was sensitive to differences in rancidity. Furthermore, the method indicated correlations between sensory measurements of rancidity and instrumental measurements.

\section{REFERENCES}

Asbridge DD. 1995. Soybean vs. other vegetable oils as a source of Edible Oil Products en Erickson DR. (Ed.) Practical Handbook of Soybean Processing and Utilization 3-6. AOCS Press, Champaign, IL.

Bi J, Ennis D, O'Mahony M. 1997. How to estimate and use the variance of $d^{\prime}$ for difference tests. J. Sens. Studies 12, 87-104.

$\mathrm{Bi} \mathrm{J}$, Ennis D. 1998. A thurstonian variant of the beta binomial model for replicated difference tests. J. Sens. Sci. 13, 461-466.

Bi J, Ennis D. 1999. The beta-binomial tables for replicated difference and preference test. J. Sens. Sci. 14, 347- 368.

Bi J, Templeton-Janik L, Ennis JM, Ennis DM. 2000. Replicated difference and preference tests: how to account for inter-trivial variation. Food Qual. Pref. 11, 269-273.

Carvajal-Zarrabal O, Angulo-Guerrero O. 1997. Effect of polyunsaturated Fatty Acids ( $n-3)$ on the lipid profile of normo and hyperlipidemic subjects. Salud Pública de México 39, 221-224.

Caiping S, Gupta M, White P. 2003. Oxidation and flavor stabilities of soybean oils with low- and ultra-low linolenic aid composition. J. Amer. Oil Chem. Soc. 80, 171-176.

Ennis DM. 1990. Relative power of difference testing methods in sensory evaluation. Food Tech. 44, 114, 116, 117.
Frankel EN. 1998. Lipid Oxidation, Vol. 10, Oily Press Ltd., Dundee (Scotland).

Gomez-Alonso S, Salvador MD, Fregapane G. 2004. Evolution of the oxidation process in olive oil triacylglycerol under accelerated storage conditions (40-60 C). J. Amer. Oil Chem. Soc. 81, 177-184.

Green DM, Swets JA. 1966. Signal Detection Theory and Psychophysics, Robert E. Krieger Publish. Co., Huntington (N.Y.).

Hawrysh Z J, Erin MK, Kim SS, Hardin RT. 1995. Sensory and chemical stability of tortilla chips fried in canola oil, corn oil, and partially hydrogenated soybean oil. J. Amer. Oil Chem. Soc. 72, 1123-1130.

Henning GJ. 1976. Objective Methods for Food Evaluation, 155-177. National Academy of Sciences, Washington, DC.

Jacobsen Ch. 1999. Sensory impact of lipid oxidation in complex food systems. Fett/Lipid 101, 484-492.

Kellens M. 1997. Current Developments in Oil Refining Technology, 31-48. Technical Report of SmetBelgium, Antwerp (Belgium).

Lawless HT, Heymann H. 1998. Sensory Evaluation of Food: Principles and Practices, Chapman and Hall, New York.

Lusas EW, Hernández E. 1993. Principles of Analysis and Quality Control of Oil Extraction and Processing en Lusas EW, Hernández E, Watkins LR and Dotoy SC. (Eds.) Vegetable Oil Processing 22.

Malcomson LJ. 1995. Organization of a Sensory Evaluation Program en Warner K and N.A.M. Eskin NAM. (Eds.) Methods to Assess Quality and Stability of Oils and Fats Containing Foods 3, 37-49. American Oil Chemists' Society, Champaign, ( IL).

Medina-Juárez LA, Gámez-Meza N, Ortega-García J, Noriega Rodríguez JA, Angulo-Guerrero O. 2000. Trans fatty acid composition and tocopherol content in vegetable oils produced in mexico. J. Amer. Oil Chem. Soc. 77, 721-724.

Morales M T, Rios JJ, Aparicio R. 1997. Changes in the volatile composition of virgin olive oil during oxidation: Flavors and off-flavors. J. Agr. Food Chem. 45, 26662673.

Norma Oficial Mexicana NOM-F-252. 1985. AlimentosAceite Comestible puro de Soya. Secretaria de Comercio y Fomento Industrial, México, D.F. 5.

Nor Aini I, Abdullah A, Halim AH. 1992. Evaluation of palm oil quality: correlating sensory with chemical analyses. J. Amer. Oil Chem. So, 69, 272-275.

Official Methods and Recommended Practices Vol I and II. 1994. American Oil Chemists' Society. 4th edition. AOCS Press, Champaign (IL).

O'Mahony M. 1986. Sensory Evaluation of Food: Statistical Methods and Procedures, Marcel Dekker Inc., New York (NY).

Thompkins C, Perkins EG. 1999. The evaluation of frying oils with the p-Anisidine value. J. Amer. Oil Chem. Soc. 76, 945-947.

White P. 1995. Conjugated Diene, Anisidine Value, and Carbonyl Value Analyses en Warner $\mathrm{K}$ and Eskin NAM Methods to Assess Quality and Stability of Oils and Fat-Containing Foods, American Oil Chemists' Society, Champaign (IL).

World Major Oilseeds: Area, Yield, Production by 19962003. http://www.soyatech.com. (Accessed August, 2004).

Recibido: Febrero 2005 Aceptado: Julio 2005 